\title{
Pedro Claver, Esclavo de los esclavos (II)
}

\section{Pedro Trigo, \\ Centro Gumilla, Caracas, Venezuela.}

\section{Dedicación a los enfermos}

La segunda dedicación asidua de Pedro Claver, a la que en parte ya nos hemos referido, son los enfermos. La mayor parte de ellos eran, obviamente, negros por ser los más abandonados, los que soportaban trabajos más duros y en condiciones de vida menos sanas. Pero también había españoles pobres, y también se enfermaban los que estaban en buena posición. A los hospitales, sin embargo, sólo iban los pobres o, a lo más, gente popular. Al Hospital de San Lázaro debían ir todos los leprosos, por ley, aunque los de buena posición, si por excepción se enfermaban, se recluirfan en alguna dependencia aislada de su mansión o en una hacienda de su propiedad. Hablaremos, pues, de la atención al Hospital de San Sebastián, llevado por los hermanos de san Juan de Dios, al de San Lázaro para leprosos, y de la atención a enfermos, que yacian en cuartuchos aislados, o a esclavos, que vivían en casa de sus amos o a los propios amos'.

1. Los textos hacen referencia a la obra de Alonso de Sandoval, Un tratado sobre la esclavitud, Alianza Universidad, Madrid,1987. Sobre su asistencia al Hospital de San Sebastián, vease pp. 123, 124, 240-243, 249, 251-253, 257, 272, 276-292. Sobre sus visitas al de San Ĺ́zaro véase, pp. 243-250, 252-253, 256, 260-262, 264-272, 274$275,279,315$. Sobre las visitas a los enfermos en sus casas, véase pp. 202-203, 232233, 236-240, 257, 262-265, 292-294, 313-315, 327, 330, 332, 338, 381-384, 386, 388-393, 396. 


\subsection{Servicio en el Hospital de San Sebastián}

\section{3:1.1. Servia como un religioso más de san Juan de Dlos}

De la comunidad de san Juan de Dios, dice el hermano Nicolás, que eran "sus más dilectos amigos". "Era muy singular el amor y afecto que mostraba a los religiosos de San Juan de Dios, hablándoles muy amorosamente y abrazándolos con grandísima humildad y sumisión donde los veía o encontraba, movido sólo por la gran caridad que ejercían con los enfermos"'. El prior le llama "general arnparo de este Hospital", y por eso dice que la comunidad en pleno asistió a su funeral, "sin llamada ni invitación, por el gran afecto y lo mucho que estimaban al padre"s. Otro religioso dice que cuando estaba fuera de la ciudad de misión lo "sentían mucho, tanto los religiosos de este Hospital como los pobres; porque era consuelo de todos, tanto en lo espiritual como en lo temporal. Y cuando regresaba [...] era recibido por todos con general alegría y aplauso; y él venía muy contento a su centro que era este Hospital"6. Otro dice que a la hora de la comida o la cena servía como un religioso más de san Juan de Dios, obedeciendo puntualmente al que comandaba la operación?. Sobre todo, los religiosos le agradecían cuando venfan las armadas, porque entonces los enfermos podían llegar hasta novecientos y ellos no se daban a basto. "En esos tiempos el padre venfa a ayudar, no sólo a repartiries la comida, confesarlos, administrarles los sacramentos y darles la Extrema Unción, sino también a desempeñar los otros oficios de tenderles las carnas y demás"日.

Atendía especialmente a los más enfermos y a los de enfermedades más repugnantes y contagiosas. Los religiosos se impresionaban de que no tenía ningún cuidado al contagio, ni daba muestra de repugnancia. Dicen que se vefa que lo hacía con gusto, con amor misericordioso y tierno, como "un hombre muy tocado de la mano de Dios"'.

Más aún, no parecía cansarse y eso que nunca comía ni bebía nada, a pesar del trajín tan excesivo y el calor tan intolerable. Dicen que "todo lo encaminaba a que se dirigieran a Dios de todo corazón"10. "Y es cierto -dice otro- que fue grande el fruto que recogió en servicio de Dios Nuestro Señor, reduciendo muchas almas a su santo servicio con el ejemplo de su santa vida y con saludables consejos"'".

2. Ibrd., p. 453.

3. Ibid., p. 240.

4. Ibrd., p. 289.

5. Ibid., p. 480.

6. Ibid., p. 282.

7. Ibrd., pp. $280,281$.

8. Ibrd., p. 286.

9. Ibid., p. 283.

10. Ibid., p. 282

11. Ibrd., p. 287. 


\subsubsection{Cuidado de los cuerpos y de los ánimos}

Pero también observan lo cuidadoso que era de la atención a sus cuerpos, cuidando que estuvieran cómodos y limpios y que hicieran todo lo posible por sanarse. Hay muchos testimonios sobre remedios que él mandaba y sobre su tenacidad en atender hasta que salían del peligro, o su conocimiento de cuándo la enfermedad era mortal. El médico más afamado y asiduo al hospital dice al respecto que, a veces, daba por desahuciado a un enfermo, " $y$ sin pena pedfa al padre que dijera su patemidad lo que juzgaba. Muchísimas veces decía el padre a este testigo que asistiera tal y tal enfermo, y que aplicara los remedios posibles; que mientras tenía el alma en el cuerpo era contrario a la caridad dejar de aplicar remedios; y notó este testigo que los enfermos por los que decía esto se sanaban y se levantaban sanos. Y tiene por cierto que fue cosa sobrenatural el sanar a muchos de los enfermos"'2. Más aún, añade que "tenía tanta confianza en el padre, que tenía por cierto que nada les podía dar que no fuese saludable para los enfermos por la mucha caridad y amor de Dios con que lo hacía"'3. Es cierto que observaciones que él hace sobre los síntomas, aún hoy parecen congruentes. Así, pues, tenía una atención muy pormenorizada al estado del enfermo.

También se cuidaba, más aún si cabe, de su estado de ánimo. Tenía gran capacidad para consolar y animar. En esto empleaba muchísimas horas. Parece congruente que esta actitud contribuiría mucho a que los enfermos cobraran ánimo y sanaran. Los religiosos notan ese contraste: que él toleraba los malos olores con toda fortaleza como si fuera de bronce, $\mathrm{y}$ "al mismo tiempo era muy compasivo con los enfermos y se dolía mucho de ellos cuando le decían que los molestaba algún mal olor. Para confortarlos y refrescarlos les ungia las narices y las muñecas con vinagre disuelto en agua"14. Lo mismo dicen cuando alguien estaba impedido de comer: "le daba los bocados con sus mismas manos sin escrúpulo ni náusea alguna, antes mostrando en eso gran caridad y fratemal amor"'ls. Parecería que al estar volcado en las personas, no le quedaba atención para reparar en cómo le afectaba a él el estado físico en que se encontraban.

No sólo iba él. Siendo maestro de novicios de los hermanos jesuitas, dos veces a la semana iba con todos ellos, escoba en mano, al hospital, para tender las camas, barrer las salas, distribuir las comidas y limpiar los platos, además de lo que él hacía como sacerdote: confesar y llevar los óleos y consolar a los enfermos ${ }^{16}$.

12. Ibld., p. 291.

13. Ibid.

14. Ibrd., p. 282.

15. Ibrd., p. 283.

16. Ibrd., pp. 249, 251. 


\subsubsection{Trasunto del amor gratuito y personalizado de Dios}

Quiero insistir que lo que comanda esta tenaz energía es la atención integral al enfermo. Para él, el objetivo último era que el enfermo llevara la enfermedad como buen hijo de Dios, que se sirviera de ella para progresar en las virtudes y vencer los vicios y, si es caso, que muriera como verdadero cristiano. Pero como esto lo hacía por amor al enfermo, porque sabía que en eso consistía su bien definitivo, ese amor relucía en todo: en su actuación de diligente enfermero para curar su enfermedad y en su atención personalizada. Como la enfermedad, si es contagiosa o repugnante, suele retraer a los demás y aislar al enfermo, él mostraba que le interesaba la persona, venciendo la repugnancia y la prevención, y volcándose sobre el que estaba necesitado, no sólo de alivio, sino de cercanía humana.

Los enfermos percibían que sólo quería su bien. Por eso, cuando les hablaba de Dios o les proponía la confesión, comprendfan que eso también lo hacía por su bien. Era claro que no les proponía la confesión para cumplir con su oficio, como también lo era que no se empeñaba tanto para hacer méritos, buscando su propio provecho y perfección. Todos notaban la alegría del encuentro, la entrega personal a ellos. Así, Pedro Claver era para ellos el trasunto de ese amor de Dios de que les hablaba y de ese Cristo que les predicaba y con el que buscaba ponerlos en contacto. En esto consiste la calidad evangélica de su dedicación a los hospitales y, en general, a los enfermos.

Esa caridad como expresión de trascendencia fue lo que vieron piratas ingleses capturados o moros en estado de semiservidumbre; y por eso, a pesar de su contumacia, acabaron rindiéndose a ella y convirtiéndose, "por los consejos y santas exhortaciones del padre, y por la humildad con que lo asistió en su enfermedad"17. También se convirtieron, por lo mismo, pecadores públicos y gente que hacía muchos años habían dejado el sacerdocio y la consagración religiosa ${ }^{18}$.

\subsection{Atención integral a los leprosos}

\subsubsection{Padre y madre de todos y de cada uno}

Pero su dedicación era mayor aún al Hospital de San Lázaro, ya que el de San Sebastián tenía una comunidad muy celosa, que sí velaba por él, mientras que los leprosos estaban mucho más desasistidos. Un religioso de la Merced decía que "si no hubiera sido por el padre Pedro Claver se habrian muerto aquellos pobres"19. Respecto de este Hospital, se cuidaba de la comida, de las medicinas, de las instalaciones, de limpiarlos y darles remedios, y más aún de acompañarlos, de quererlos y consolarlos, así como también de velar por su cercanía a Dios y salud

17. lbrd., pp. 126; 125-129, 183.

18. Ibrd., p. 189.

19. Ibid., p. 260. 
espiritual y, finalmente, de ofrecerles unas exequias dignas y encomendar su alma. Era tanta su solicitud que, el limosnero del hospital, que era un enfermo de él, "venía todos los días a este Colegio por orden del mismo padre y le daba cuenta del estado de los enfermos; y el padre le daba algo para llevar, así vestidos como medicamentos; y les enviaba lo que pedían. Si alguien tenía necesidad de confesarse, al primer aviso de aquel limosnero, iba de inmediato a escucharlo"20. Así, pues, "no era sólo procurador y maestro de casa del hospital, sino también cura y pastor de él" ${ }^{21}$. En particular, les hizo una iglesia de piedra y consiguió toldillos para cada uno, para que no les molestaran los mosquitos y pudieran dormir bien. Era tal la estima que sentían por el padre que, al morir, declararon "que si hubieran muerto sus padres y madres no les causaría tanta pena como les causaba la pérdida del padre Pedro Claver; y que estaban muy dolidos y afligidos por una pérdida tan grande como la del padre, que era padre y madre de todos y de cada uno en particular"2?.

Al llegar, le salían al encuentro y él iba abrazando a cada uno. Congregados todos y puestos con la mayor comodidad posible, él en medio de todos, hacía la señal de la cruz y recitaba con ellos las oraciones. "Enseguida les exhortaba a tener paciencia y a conformarse con la voluntad de Dios. Y para que esto fuera de gran mérito ante Nuestro Señor, les decía que convenía estar siempre en su divina gracia y amistad, amándose los unos a los otros como hermanos e hijos de Dios y absteniéndose de juramentos y de todo pecado y ofensa a Dios"23. Luego, les hacía un acto de contrición muy fervoroso del que todos participaban. A continuación, confesaba a los que querian, y, para acabar, distribura lo que había traido para ellos.

Luego, iba a los bohíos de los más llagados e impedidos, y en primer lugar, los consolaba con su cercanía humana, luego les arreglaba la cama, levantándolos y aliviándolos lo mejor que podía y, finalmente, si lo deseaban, les confesaba. Todos insisten que atendía particularmente a los que, por causar hedor y horror a los demás, estaban desamparados. Con ellos estaba mucho tiempo, tocándolos, curándolos y dándoles de comer con su mano, sin ningún temor al contagio. Por lo cual los enfermos decían "que el padre no era hombre de este mundo sino del cielo"24. Esa misma admiración causaba a los religiosos que lo acompañaban de ordinario y a los seglares que lo hacían eventualmente y regresaban impresionadísimos y muy edificados. Cuando un vecino le decía que podía caer enfermo, el padre "se reía mucho de eso"2s. Todos coinciden que iba "muy alegre y contento"26.

20. Ibld., p. 245.

21. Ibid., p. 243.

22. Ibid., p. 247.

23. Ibid., p. 244.

24. Ibíd., p. 248.

25. Ibid., p. 267.

26. Ibrd., p. 266. 
Un mendigo, que se recluyó en el hospital un tiempo, dice que "el padre mostraba tanta alegria y satisfacción cuando los abrazaba como si estuviera en los más grandes entretenimientos del mundo"27. Dice que "con gran amor el padre con sus manos consagradas les limpiaba las babas y les hacía sacar la lengua y les limpiaba el humor y las costras que tenían en ella, cosa que hacía maravillar a este testigo. Se extrañó aún más al ver que, arrodillado, con su boca y lengua les lamía las llagas de sus pies y los besaba"2".

\subsubsection{Su cercanfa les hacía sentirse humanos}

El leproso, en todas las culturas, es el intocable, por antonomasia. Por eso, es normal que lo que más sientan sea el aislamiento, el desamparo. Este puede derivar, muy fácilmente, en la pérdida de autoestima, esperanza y respeto, y en la entrega a las pulsiones más elementales, sean de autodestrucción, de resentimiento o de erotización. Por eso, con certero instinto, Claver buscaba que vivieran desde su estatuto de hijos de Dios y que, al relacionarse con Dios, encontraran compañ́a y, desde ella, pudieran relacionarse entre sí como hermanos. Al mantener el respeto, también podían mantener la esperanza y hacer por curarse.

La cercanía cordial y desprevenida del padre les hacía sentirse humanos. Desde ese nivel, podían aceptar la invitación a la paciencia como un modo de dignidad. Podían llegar a aceptar que Dios no era el autor de su enfermedad, sino su compañía en ella. Es cierto que uno no se imagina a Jesús lamiendo las llagas de un enfermo, pero también es cierto que tocó al leproso. El que Claver no se contagiara es señal de que esa relación nada tenía de morbosa, sino que era cercanía maternal, como lo apreciaban los enfermos.

\subsection{Cuidado de los enfermos particulares}

\subsubsection{Una relación mutua}

Respecto de enfermos particulares abundan los casos, en los testimonios. Lo que dicen generalmente es que, si le avisaban de algún enfermo o lisiado, en particular si eran negros o negras incurables, los visitaba con regularidad, les llevaba comida y vestidos y se interesaba por su salud y les deba remedios, y los consolaba, los confesaba y, si era inminente el peligro, les daba los óleos. No sólo eso, también "entraba a una de las casas vecinas y pedfa a los dueños que por amor de Dios tuvieran cuidado del enfermo y no se olvidaran de él, enviándole algo y visitándolo de vez en cuando; que Dios se lo pagaría"29. Incluso lograba que personas piadosas tuvieran algún enfermo en sus casas para atenderlo. Por ejemplo, 
cuenta un testigo de una negra libre que tenía a otra "de caridad por orden y ruegos del padre"wo. La tuvo así seis años. Ella cuenta la última hora de la enferma. Después de haber ido varias veces el padre, le dijo el día que iba a morir. Llegado el momento, le dijo a la enferma: "Madre Ursula, mucho la ama Dios y por eso la quiere llevar a descansar, y hoy debe morir, y no tiene que quedarse en el purgatorio más de tres horas. Acuérdese mucho cuando se vea ante Dios en la gloria de rogar por mí y por esta mujer [...] a quien le es tan deudora porque ha hecho por usted más que si fuese su madre"3!.

Parecido cuenta otro testigo, que le llamó para que visitara a su padre, que estaba desahuciado. Como paś más de hora y media de estar a solas con el padre, quiso ver qué pasaba y pasando por otro cuarto contiguo se puso detrás del pabellón de su cama y lo mismo hizo su mamá "Vieron que el padre se arrodilló frente a la cama, y con las manos sobre ella le pidió que por amor de Dios le diese su palabra de encomendarlo a Su Divina Majestad cuando lo viese en el cielo, porque al día siguiente había de morir [...] Y el enfermo le dio palabra de hacer lo que le pedía; y entonces el padre le pidió que lo abrazara en señal de lo que prometía, y el enfermo lo abraz $6^{\prime 32}$. La mamá del testigo comenzó a llorar y él la consoló diciendo que lo que habían visto debía ser motivo de gran alegría. La escena muestra conmovedoramente lo que venimos diciendo: la relación del padre con los enfermos es una relación mutua y mira como horizonte último a la condición de hijos de Dios y al encuentro definitivo con él. Llevar al enfermo a que anhelara ese encuentro, felicitarse de él y pedirle que no lo olvidara, en ese encuentro tan gratificante, era convertir la muerte en tránsito a mejor vida. ¿Qué más se puede hacer por un enfermo? ¿Qué más se puede hacer para que el enfermo viva la muerte como culminación de la vida? Si la muerte tiende a ser experimentada como fin de esta vida y como soledad en el fin, ¿qué mejor antídoto y superación que una conversación asi? No puede aparecer más claro que atender al enfermo no era para Claver hacer un sacrificio por Dios, sino la relación más cristiana y humanizante posible.

Esto mismo se echa de ver en el modo como entraba a visitar a los enfermos más repugnantes e incurables, como el caso de una negra, que describe de forma pormenorizada el hermano Nicolás: "Aqur hay mucha paciencia y hay mucho sufrimiento por amor de Dios. Yo me encuentro muy necesitado de esas virtudes y vengo a buscarlas en este lugar y a aprenderlas. Enséñame, enséñame -le decíaporque vengo para aprender de ti" ${ }^{\prime 3}$. El que supuestamente viene a dar, manifiesta que viene a recibir, con lo que el paciente se convierte en dador. Claro está que, en seguida, sacaba el Cristo de bronce y se lo daba a besar para que aprendiera a tener

30. Ibid., p. 314.

31. Ibld., pp. 314-315.

32. Ibid., p. 384.

33. Ibid., p. 239. 
la paciencia del crucificado, que sufráa sin culpa y por él, y también le traía lo necesario y regalos, y lo consolaba. Pero también era cierto que el padre venía a aprender. El robustecía en el enfermo esa actitud de la que aprendía, pero también el padre aprendía del enfernno. La relación era mutua, era humanísima, era gratuita, y por eso, no humillaba, sino que enaltecía.

\subsubsection{El triunfo del amor sobre la propia debilidad}

Los testimonios abundan en cómo el padre parecía insensible a lo asqueroso. El secreto está en lo que decía a una intérprete: "muchas veces le decía a esta restigo que no tuviera náusea, pues eran nuestros prójimos" un testimonio en el cual aparece que el padre no era de bronce, pero que la determinación de hacerse projimo del que lo necesitara era tan firme que no iba a tolerar nada en él que lo apartara de ella, que fuera obstáculo para esa relación. El triunfo del amor sobre la propia debilidad es, a veces, de un dramatismo que sobrecoge: "Habiéndose enfermando una negra esclava, llamada Rufina, de muchas viruelas que causaban horror y náusea por la mucha materia y mal olor, vino el venerable padre a consolarla; sintió náusea por el mal olor de la materia y dijo: 'Cuerpo, ¿te disgusta? Pues ahora lo pagarás'. Y ordenó que le juntaran en una escudilla todas las materias que despedía la dicha enferma y habiéndolo hecho así, se acercó de nuevo el venerable padre a verla, limpiándola y enjugando la materia. Y toda la escudilla en la cual había sido puesta esa materia se la tomó, causando terror y maravilla a todos los presentes"33.

Se refieren varios testimonios a lo infatigable que era, visitando a negros enfermos, "en especial cuando había alguna epidemia de viruela en esta ciudad, que cansaba a tres o cuatro hermanos compañeros. Por eso regresaba al Colegio y dejaba al primer compañero que no podía caminar más ni moverse, y se llevaba a otro, y de esta manera cambiaba tres o cuatro compañeros cada día y él se mostraba tan incansable":36. Dos testigos, que le acompañaron cuentan un caso que revela la manera tan delicada, eficaz e integral como atendía a los enfermos contagiosos ${ }^{37}$.

También se cuentan varios casos en los cuales acudía sin ser llamado para atender enfermos de extrema gravedad y desahuciados que él decfa que el enfermo no moriría y en efecto, sanaba, y otros en los cuales se presentaba para ayudarles a bien morir. El interés por los demás provee de antenas excepcionales.

34. Ibid., p. 293.

35. Ibrd., p. 294.

36. Ibrd., p. 203.

37. lbid., pp. 233-234, 263-264. 


\section{Atención integral a los presos y condenados a muerte}

\subsection{Disponibilidad en orden a la rehabilitación}

Un tercer campo de acción, también muy extremo, en el cual Pedro Claver desbordaba su celo y en el cual se echaba de ver su fecundidad apostólica es la atención a las cárceles y, en particular, a los condenados a muerte ${ }^{38}$. No pasaba semana que no fuera a visitarlos. Como sucedía con los enfermos, les llevaba diversos regalos, los escuchaba todo lo que querfan hablar, le contaban sus casos. Si le pedían que hiciera alguna diligencia, él la hacía puntualmente, insistiendo a los abogados defensores que no omitieran ninguna diligencia, "que patrocinaran las causas de esos pobres presos" $"$. Confesaba a los que querían hacerlo, exhortándolos a ello. Luego, los reunía a todos y "les decía que era mejor pagar en esta vida las penas de los pecados que cometemos, que pagarlas en el infierno donde no hay fin ni término. Y para terminar, sacaba el crucifijo de bronce [...] y les decía que el remedio de todos sus afanes se encontraba en aquel Señor crucificado. $Y$ para que quedaran más consolados y dispuestos a soportar con paciencia los afanes, les hacfa recitar un acto de contrición muy fervoroso [...] Al despedirse, les decía que cualquiera que lo necesitara, a cualquier hora lo mandara llamar, que lo asistiria con mucho gusto y puntualmente lo atender $\left\{a^{\prime \prime 40}\right.$. A los que estaban en celdas de castigo, los visitaba durante mucho tiempo, consolándolos.

Como vemos, también aquí la relación es realista, humana, integral. Ante todo, los insta "a soportar con paciencia su encierro"4l. Luego, los escucha, ya que el condenado tiene su versión de lo sucedido y quiere darla a quien juzga imparcial y humano. En este punto, el condenado no espera respuestas, sino sólo que la escucha sea real. Después viene ayudar al que crea que todavía se puede hacer algo, y consolar a todos con palabras y con obsequios. Los que están en la cárcel, bastante castigo tienen con estar allí; por eso, el que se les trate humanamente y no como monstruos es fundamental para evitar que lleguen a serlo o para lograr que dejen de serlo. Luego, la propuesta de la confesión. Este acto es crucial para el preso: es confesar la verdad ante Dios. Sólo confesándola, puede darse la reconciliación de uno consigo mismo y la rehabilitación personal. El presentar a los condenados al Condenado tiene un significado muy especial: él les puede comprender y con él se pueden desahogar. Para los que están encerrados, saber que pueden disponer de una persona que está libre, es muchísimo, es un sacramento de dignidad, reconocimiento y esperanza. Por eso, la despedida de Claver es tan significativa.

38. lbid., pp. 294-312.

39. Ibrd., p. 295.

40. Ibrd., pp. $295-296$.

41. Ibrd., p. 295. 


\subsection{La oportunidad de redefinir definitivamente su vida}

La atención al condenado a muerte condensa con la mayor fuerza posible todo lo dicho hasta ahora. Toda la relación con él iba encaminada a que olvidara toda su vida pasada y todo lo que hay exterior a él y se concentrara en ese momento supremo. Le insistfa en que "el camino que debŕa recorrer era muy largo y el tiempo muy corto, que así era necesario animarse con el incentivo de la consideración, y hacer muchos actos de verdadera contrición"42. Le ponía en la mano un crucifijo con un Cristo pintado y le decía: "Este es el madero con el que has de huir de esta gran borrasca y no tienes otro remedio para librarte de ella que abrazarte a esta cruz. no perderla de tu vista y abrazarte a ella pues allí está tu salvación"43. Lleva, pues, al condenado a que haga del morir el acto que defina su vida. Por eso, debe olvidarse de todo y concentrarse en ese paso. No debe vivir su muerte como víctima, poseído por el terror, el abatimiento y la malevolencia con la sociedad, que va a acabar con su vida. El tiene la oportunidad de definir su muerte y así rectificar y sellar toda su vida. Por eso, le pone en la mano, como compañero, a otro ajusticiado, que vivió el suplicio como su acción más consumada. Jesús consumó su vida, él debe rectificarla. Para eso murió Jesús. Y para eso está el padre a su disposición todo el tiempo, hasta que muera.

El tiene la oportunidad, que no tiene casi nadie, de definir su vida. Por eso, le dice el padre sin ironía: "Tienes suerte, hermanito mío, de saber el día en el cual debes morir. No te queda otra cosa que tener buen ánimo"4t. Por eso, le dice también a él, como a los agonizantes: "Afortunado sería yo si me llevaras contigo" ${ }^{\text {.4 }}$. El quiere vivir el último momento con esa capacidad de decidir, que se le ha ofrecido al condenado. Todo el empeño de Claver es que ésta sea la clave del tránsito, que el condenado la haga suya. Este planteamiento es en realidad, grandioso. El presupuesto es que el crimen no define al criminal. Dios le da realmente la oportunidad y la fuerza de redefinir su vida. Claver no es, obviamente, representante de la ciudad, sino del Dios, que no quiere la muerte del pecador, sino que se convierta y viva, del Buen Pastor, que no escatima ningún esfuerzo para rescatar a la oveja perdida.

\subsection{Ayudar a que muera la muerte de un perfecto cristiano}

Después de esta preparación, "oŕa la confesión general del condenado por largo tiempo. Enseguida, si la hora lo permitra o si no al dra siguiente, le celebraba misa, le daba la comunión y recitaba sobre él un Evangelio [...] y no lo dejaba de ninguna manera ni de día ni de noche, asistiéndolo y animándolo sin cesar"46.

42. lbid., p. 296.

43. Ibid.

44. Ibrd.

45. Ibid.

46. lbid., p. 296. 
Mientras le ponían los vestidos y las cuerdas "eran tantas las palabras tiernas que pronunciaba, que endulzaba en aquel paciente aquella hiel arnarga y [...] enternecía a todos los presos que se encontraban presentes" ${ }^{\text {" }}$. Cuando iban por la calle, al suplicio, daba lugar a otros sacerdotes y religiosos para que lo confortaran. En los cruces de calles, donde se aglomeraba la gente, "hacía que el condenado se detuviera y hablara al pueblo, pidiéndole perdón del mal ejemplo que había dado y que aprendiera de él a no ofender a Dios"4t. Mientras caminaban, lo iba rociando con agua bendita y le refrescaba la nariz con agua perfumada. "Al llegar al lugar del suplicio le hacía besar la escalera como el instrumento por el cual debía subir a gozar de Dios; y allí, con sus propias manos, le limpiaba el sudor del rostro y le daba algunos bocados que llevaba listos para que no se desmayara en tan amargo momento. Después de haberlo reconciliado y absuelto por medio de la bula, dándole mil abrazos lo consolaba y animaba, diciéndole que ojalá el fuera tan afortunado de ir con él al cielo; y con la misma caridad y celo que se ha dicho, no lo abandonaba hasta que no había muerto. Mientras agonizaba hacía que se le cantasen con música preparada en la catedral, un responso con el órgano y con todos los instrumentos necesarios para ello"49".

Claver quiere lograr la muerte de un perfecto cristiano. El, con su compañia, que no recrimina, sino que reconcilia y rehabilita, es el sacramento de la acogida de Dios. Y asf, el reo, que dio mal ejemplo, es capaz de dar ahora buen ejemplo. Y Claver lo conduce a que afronte la muerte con valor, como expiación de sus culpas, y más aún, como tránsito a los brazos del Padre, tránsito al cielo. Nada le dice de seguir purgando, bastante amargo es el trago de la ejecución. Y por eso, como propio de persona digna, solemniza su agonía con canto y música de variados instrumentos, incluido el órgano. La ejecución, que era un acto doloroso $y$ afrentoso, presenciado por la multitud, proclive a verlo como una venganza, se transforma en el acto de rehabilitación final del reo, que es así, más aún que paciente, actor. La música corea como un aplauso el buen desempeño del ex criminal. Esta sobredeteminación del acto redime cambién a la justicia de la ciudad, que no busca sólo el restablecimiento del orden, por el castigo del trasgresor, sino también la rehabilitación del reo, con lo cual se restablece no sólo el orden extemo, sino el interno, quedando ya no sólo sellada la fuente del desorden, sino trasmutada en fuente que mana humanidad. Hay que hacer notar al respecto que eran los alcaldes de la cárcel los que llamaban al padre, en cuanto notificaban la sentencia de muerte a un preso.

47. Ibid., p. 297.

48. Ibid.

49. Ibid., p. 297. 


\subsection{A favor de la persona: no trataba a nadie como reo}

Los casos que se narran son muy dicientes de la humanidad extrema de Claver, que de lo extremada que era, podía dar la impresión de que se ponía a favor del reo, que no lo trataba como tal. Por eso, cuando un religioso le reprocha que lo que está haciendo no es regular, le responde: "Si no incurro en alguna irregularidad dejándolo, mucho menos seré irregular ayudando a salvar a esta alma"so. Es, como en el caso de las disputas de Jesús con los fariseos, la discusión sobre si debe prevalecer la normativa o el bien úitimo de la persona, fin al cual debe enderezarse cualquier normativa, en una sociedad cristiana.

Esto reluce más aún en su trato con los condenados por la inquisición. Aunque le parecía que las procesiones de penados hacfan fruto $y$, en ese sentido, eran saludables, "con todo sentía gran compasión por los reos procurándoles, en cuanto podra, el consuelo espiritual y temporal de sus almas y cuerpos, exhortándolos a que soportaran con paciencia, silencio y humildad aquellas penitencias"si. El padre se unía a la procesión y se acercaba a los penitenciados. "Ellos se alegraron mucho al verlo, y algunos decfan: 'Padre, encomendadme a Dios' y otros: 'Celebrad una misa por mí, y él respondía que lo haría con mucho gusto"32. Y les llevaba regalos a la cárcel y los consolaba y animaba a la paciencia y tolerancia.

Es un toque de realismo su llamado al silencio, ya que alegar algo en su defensa, serfa considerado como contumacia. Pero Claver no aludía al silencio motivado por el miedo o el engreimiento $y$, por eso, inculcaba también los sentimientos de humildad, aceptando la propia falibilidad, y tolerancia, aceptando la de los demás, y encomendando todo a Dios. Es de notar que muchos funcionarios del Santo Oficio testificaron a su favor, reconociendo su santidad.

\section{La fuente de su apostolado}

La pregunta obligada, después de este recorrido, es cuál era la fuente de la cual manaba tan abundante, constante, pura y nutritiva el agua de su caridad. Se ha visto claro que para Pedro Claver, el colmo de la caridad es poner a las personas en contacto con el Dios amor, padre materno, todo misericordia, acogida, ternura y plenitud. Esto era asf, porque Dios era la vida de su vida, el que la salvaba y ponía a valer, el que la colmaba.

\subsection{Embebido en Dios}

Los testigos destacan que todo el tiempo que le sobraba a Claver del trato con los prójimos necesitados, lo dedicaba al trato con Dios, con la Virgen, con los santos, pero sobre todo, con Jesucristo. Es voz común en los testimonios,

50. Ibid., p. 299.

51. Ibid., p. 301.

52. Ibrd., pp. 301-302. 
"que todo el día iba embebido en Dios y buscando maneras de inflamar su amor sacando motivos para hacerlo de todo aquello que veía"s3. Uno de los rectores del colegio decía, refiriéndose a su oración, "que no sabía cuándo la interrumpía el padre. Porque a cualquier hora que lo fuera a visitar a su cuarto lo encontraba en oración"su. Otro seglar dice que "vio siempre que el padre permanecía en continua oracion durante todo el día y la mayor parte de la noche"s5. Y el barbero del colegio, que tenía mucho trato con los padres, comenta que "cada vez que lo buscaba para algún asunto, lo encontraba en oración y en contemplación"s6. Un familiar del Santo Oficio declara que "cada vez que este testigo iba a visitarlo en su aposento, lo que hacía con mucha frecuencia, lo encontraba en oración"s7. El hermano Nicolás declara pormenorizadamente cómo hacía la oración y lo resume diciendo que "el tiempo en que no estaba ocupado en atender al bien espiritual de las almas confesando o catequizando o instruyendo a los negros, lo empleaba en la oración y comunicación con Dios"s8 y sostiene "con gran fundamento que casi toda la noche pasaba en ella"s9. Bastantes mencionan que "estaba muy amobado y casi fuera de sí de manera que no notaba la presencia de este testigo ni lo oía cuando le hablaba"60.

\subsection{Piedad popular barroca}

Podemos decir que su religiosidad era la religiosidad popular, la piedad católica barroca. Y asi, el hermano Nicolás se refiere a su devoción tan jugosa a la Virgen, que incluye la práctica del rosario y la difusión de esa devoción, tanto es así que tenía montada una verdadera fábrica de rosarios, que distribuía con profusión y eran muy estimados por venir de él ${ }^{61}$.

También tenía gran devoción a la cruz. En todos los apostolados sacaba a relucir el Cristo de bronce que llevaba consigo y que daba a besar a los enfermos y necesitados de consuelo o contrición. Tenía una cruz tosca de madera al pecho que estimaba muchísimo y daba a las personas cuando el caso era desesperado, pidiendo que se la devolviesen, y la cruz, según aducen varios testimonios, hizo curaciones ${ }^{62}$. Cuatro años antes de morir pasaba el virrey del Perí a los reinos de España y quiso visitar al padre por la fama de santidad que tenf́a.

53. Ibid., p. 75.

54. Ibid.

55. Ibid., p. 76.

56. Ibid., p. 78.

57. Ibid.

58. Ibld., p. 72.

59. Ibid.

60. lbid., p. 73.

61. Ibrd., pp. 334-338.

62. lbrd., pp. 338-339, 411-412, 228. 
Después de intentar en vano besarle la mano, le pidió que le encomendara a él y a su farnilia, lo que el padre le prometió. Le pidió que en prenda le diera algo suyo. El "le contestó que era pobre y no tenía nada para darle". Entonces, el rector le preguntó al hermano Nicolás que qué tendría el padre para darle, y él le dijo que lo que más apreciaba era esa cruz de madera. El ordenó que se la trajera y diera. "El padre, como tan obediente que era, fue inmediatamente por la cruz y la llevó al señor marqués diciéndole que se la daba de muy mal gusto porque había sido siempre su médico y su medicina" ${ }^{\text {"6i3 }}$. Como en otras ocasiones, reluce aquí tanto el aprecio que tenía a esa cruz como el poco aprecio a las grandezas sociales, y por eso, la franqueza de decirle que se la daba por obediencia, ya que le parecía el acto como una frivolidad, como lo era realmente, aunque el marqués no pudiera captarlo y lo tomara con devoción y sumo aprecio, diciendo "que la estimaba más que un toisón"

También era muy devoto del agua bendita y rociaba con ella a los enfermos y a los condenados. También él se santiguaba siempre con ella y tenía cuidado de que no faltara en el templo ${ }^{65}$. Igualmente, lo era de las ánimas, del ángel de la guarda, del santo de su nombre, de san Ignacio, santo Domingo y san Antonio Abad ${ }^{66}$. También asistía con devoción a los sermones, a la imposición de ceniza, a las disciplinas de cuaresma con sus correspondientes ejemplos predicados, a la bendición de las palmas el domingo de Ramos...

\subsection{En toda su vida se crucificó a imitación de Cristo}

Pero lo más característico suyo, lo que da su fisonomía espiritual, es su contemplación constante de la pasión de Jesucristo: "Lo que meditaba con mayor frecuencia era la oración del Huerto, los azotes en la columna, el escarnio de la coronación de espinas, la crucifixión del Señor y el descendimiento de la cruz"67. Tenía estampas de cada paso de la pasión. Dejaba todo el día el libro abierto en su cuarto, en el paso que contemplaba. Le dijo al hermano Nicolás "que muchas de sus mortificaciones y penitencias las hacia en reverencia y memoria de la Pasión"6r. Varios atestiguan haberlo sorprendido en su cuarto con una corona de espinas de cedro en la cabeza y una soga al cuello ${ }^{69}$. También se azotaba al acostarse a las nueve y al pararse hacia las cuatro de la madrugada. Lo hacía tan prolongadamente y con tal intensidad que hasta un vecino testifica que la oía habitualmente.

63. Ibid., p. 340.

64. Ibid.

65. Ibid., pp. 240-241.

66. Ibíd., pp. 241-243.

67. Ibid., p. 68.

68. Ibid., p. 69

69. lbid., pp. 75-75, 165-166. 
Además del libro de estampas, tenía en su cuarto cuadros de la pasión, "de manera que adonde quiera que se volviera tenía algo que le recordaba estos misterios"70. También tenía cruces de madera con un Cristo pintado para llevarlas a los enfermos y condenados. En la capilla frente a su confesionario, colocaba el hermano Nicolás cuadros de la pasión, que él mostraba a los penitentes más rudos o poco dispuestos, exhortándolos a penitencia. Acababa siempre con un acto de contrición muy fervoroso, golpeándose el pecho, mientras les mostraba el Cristo de bronce, repitiendo muy sentidamente: "Señor, yo te quiero mucho" 1 . Los penitentes acababan repitiéndolo con él con verdadero dolor de sus pecados. Era tan devoto de la pasión que quería que todos lo fueran y recomendaba esta devoción a sus penitentes y amigos. Más aún, se puede decir que toda su vida fue "imitar a Cristo en sus dolores y sufrimientos. Tenía grabadas e impresas en el corazon las insignias de la pasión, y a Cristo Crucificado con ellas. Porque en toda su vida se crucificó a imitación de Cristo"72.

Esta crucifixión se manifestaba en la pobreza absoluta, que es la característica externa en la que todos se fijan, ya que nadie lo vio con sotana nueva, sino siempre viejas y remendadas, aunque limpias. En su cuarto no tenía sino una mesa y una silla viejas y un taburete, en el que se sentaba. No dormía en la cama, sino cuando estaba muy enfermo. Como le dijo al marqués, "era pobre y no tenúa nada". Y nada necesitaba. Su crucifixión se manifestaba también en su obediencia, ya que para todo pedía permiso muy minuciosamente y obedecía en lo que se le mandaba, como cuando le ordenó el provincial quitarse los cilicios, después de una de sus enfermedades. Se manifestaba en la perfecta mortificación de todos los sentidos, empezando por la vista y el ordo, de tal manera que no se enteraba de lo que no tenía que ver con su misión, ni tenfa curiosidad de ello. También hemos visto cómo se mortificaba en el olfato y el gusto, ya que ni en las fiestas se los daba en el comer. Pero la crucifixión era sobre todo de su amor propio. Por eso dicen varios testigos que, cuando hablaban bien de él huía, que cuando le pedran que los encomendara, presuponiendo que estaba más cerca de Dios, respondía que era una mala recomendación, que les podía hacer mal. El se tenía por el hombre más bajo y ruin del mundo.

\subsection{Cuerpo mortificado, cuerpo liberado}

Teniendo en cuenta el apostolado tan desgastante, y digamos, sobrehumano, que ejercía, parecería que las penitencias tan excesivas estaban totalmente fuera de lugar. Demasiada penitencia eran las fatigas apostólicas. Más aún, su médico insiste que las enfermedades que tuvo tenían como causa "el mal trato que daba a su cuerpo con muchas abstinencias, disciplinas y cilicios y otras mortifica-

70. Ibrd., p. 69.

71. lbid., p. 70.

72. lbid. 
ciones que hacía" "7. Pero, mirando más de cerca, habría que reconocer que durar treinta y ocho años en este apostolado, que hemos descrito, en los calores de "Cartagena, es durar muchísimo tiempo. Así, pues, no se puede decir que le hizo mal su modo de vivir.

Pero el fruto de su mortificación fue, como dijimos, que su cuerpo no sólo no fuera obstáculo para el apostolado, sino que se volcara completamente en él. Si el cuerpo tiene la función orgánica y la función simbólica, se puede decir que Claver logró que lo primero se redujera al mínimo y que lo segundo desaguara del todo, en la relación con el prójimo. Así dicen muchos testigos que su semblante parecía el de una persona sin vida. Sin embargo, todos los testimonios coinciden en que con los pobres y enfermos, con los esclavos recién venidos y con los leprosos estaba de lo más comunicativo, que irradiaba cariño, que su rostro relucía de alegría y fervor. Es lo que dice Pablo a los Corintios: "paseamos continuamente en nuestro cuerpo el suplicio de Jesús, para que también la vida de Jesús se trasparente en nuestro cuerpo [...] Así la muerte actúa en nosotros y la vida en ustedes" $(2 \mathrm{Co} 4,10.12)$.

Es muy claro que la ascesis que practica no es ni masoquismo, ni encierro en sí mismo, sino, por el contrario, liberación personal para entregarse con una humanidad consumada a los que tenían necesidad de él, sobre todo a los que estaban abandonados y eran despreciados. El no necesitar nada se convierte en estar dispuesto siempre a dar el evangelio y a darse a sí mismo; la mortificación de los sentidos se transforma en cuidado de los sentidos enfermos; la abstinencia absoluta da lugar a la dadivosidad y el regalo a los necesitados. Así, el que nada tenía para sí, tenía el cuarto lleno de cosas para dar a otros. Incluso en el confesionario tenía una despensita, en la que no faltaba el vino, para dar a los que precisaban un bocado, y más todavía, un detalle de delicadeza humana.

Y sobre todo el que no se enteraba de lo que pasaba en la ciudad, ni alrededor suyo, tenía una tremenda capacidad para estimular la misericordia de la gente, para implicar a muchas personas de modo ocasional y, más aún, sistemático, en su servicio a los más pobres. El hacía, y de modo excepcional, pero también buscaba muchos colaboradores como un modo espléndido de multiplicar la caridad, contagiándola. Iba constantemente a pedir, a veces cosas, a veces implicación personal. Y sabía agradecer, sirviendo también espiritualmente a esas personas. Son muchos los testimonios de gente que se siente agradecida de que el padre echara mano de ellas y se ve que lo hacían desde dentro, participando también de su misión espiritual.

73. Ibid., p. 367. 
El que la mortificación no lo ensimismara se ve sobre todo en los banquetes que lograba que le prepararan los días de grandes fiestas para los pobres, en la puerta del colegio, y para los leprosos, en San Lázaro. El, como Jesús, servía la mesa con gran alegría y daba con su mano la comida a los impedidos. $Y$ al final, recogía y lavaba todo con ayuda de los intérpretes. Estos banquetes son verdaderos sacramentos del reino y manifiestan que la mortificación era para reservar para esto todas las energías de su vida. Lo mismo podemos decir de la relación tan cálida con sus más directos colaboradores: los hermanos que lo acompañaban y los intérpretes negros. Los llenaba de respeto, los quería, los mimaba. Y logró que ellos participaran realmente de su ministerio. En los testimonios tan abundantes que dan, manifiestan estar a la altura del padre y expresan el inmenso respeto y cariño que sentían por él.

Así, pues, el mortificadísimo Pedro Claver, el que parecía un hombre que no era de este mundo, insensible a la fatiga, al horror de los cuerpos enfermos, fue también una persona muy sensible, que se la pasaba abrazando y acariciando a los esclavos y enfermos pobres, que les hablaba con infinita ternura, que cuando hablaba de Dios se inflamaba de tal modo en amor que lo contagiaba.

La ascesis fue, en verdad, muy extrema. Tenfa que serlo, ya que su apostolado lo fue más aún. Ese fue el modo que tuvo de unificar su persona para que no viviera sino para amar a Dios y para hacerse prójimo de los que habían cardo en manos de ladrones, que los habían dejado medio muertos. Jesús crucificado y los crucificados del mundo fueron su vida. La ascesis fue el modo de no desviarse de esa dedicación; la practicó para no distraerse de ella, para no llevarla a cabo de modo remiso a causa de resistencias intemas.

Todo esto se patentiza en su muerte: hab́a vivido prescindiendo de él mismo y volcándose sobre los demás, y al final, cuando ya está muerto, todos se vuelcan sobre él. Así tiene que ser para que se consume la gratuidad. El defendió celosamente su humildad, y por eso, fue bueno que el homenaje, que llega a la apoteosis, tenga lugar después de la muerte. El habf́a rehusado sistemáticamente que le besaran la mano, y ya muerto se la besan durante dos días enteros. Incluso, afirman los testigos, que su mano no estaba rígida, sino muy maleable y hasta impregnada del buen olor de su vida. El, pobre de solemnidad, vivió dando todo lo que conseguía para dar y dándose a sí mismo, y ya muerto, lo quieren despojar de todo, para retenerlo de ese modo consigo. Acaba, literalmente, entregado, un cuerpo entregado, completamente simbólico.

\subsection{La prudencia de Pedro Claver}

Hablamos de lo escandaloso que resulta el hecho de que no haya ningún testimonio de compañeros jesuitas sacerdotes. Es comprensible que los padres se hubieran sentido muy contrariados por el proceder de Claver, por varios motivos muy significativos. Respecto de su apostolado, a todos les parecía bien su dedi- 
cación a los negros, ya que no sólo era el destino que le había dado la obediencia, sino un apostolado particularmente entregado a la Compañía; pero la preferencia sistemática de los negtos respecto de los blancos, resultaba inadmisible, en una sociedad de castas y esclavista. El que irrumpiera en el templo una multitud de negros, comandada por él, para oír la misa, hacía que se salieran de forma automática, casi todas las personas de buena sociedad, sobre todo las mujeres ${ }^{74}$. Esto tuvo que molestar muchísimo a los compañeros, porque les espantaban las devotas. El que discriminara de manera sistemática a los blancos, en el confesionario, también ${ }^{75}$. Si todavía extremaba el rigorismo, al recriminar a las mujeres, porque venfan con trajes llamativos y, sobre todo, con guardainfantes, se convertra en una actitud intolerable. Consta que el rector le reconvino de forma airada en el templo, delante de muchos testigos, por decir a una penitente que, si quería confesarse con él, viniera vestida más de manera modesta. Esto habría que interpretarlo como la gota que rebaso su paciencia, su nivel de tolerancia.

El modo tan cariñoso de tratar a los esclavos, abrazándolos y acariciándolos, el darles no sólo medicinas y comida, sino golosinas, tabaco y bebida, el que tuviera una verdadera despensa de todo esto en su cuarto e incluso en el confesionario, el que les procurara suculentos almuerzos, en las fiestas, y comiera con ellos, sirviéndolos a la mesa ${ }^{76}$, les tenía que parecer impropio de un sacerdote y contrario al modo de proceder, tan grave, de un sacerdote jesuita. Este detalle de dar no sólo cosas necesarias, sino golosinas, tabaco y bebida impresionó incluso al abogado del diablo del proceso de beatificación ${ }^{\pi}$.

El que honrara a los esclavos intérpretes, colocándolos por encima de él ${ }^{78}$, el que los llevara a su cuarto para atenderlos, cuando estaban enfermos ${ }^{79}$, les tenía que parecer algo revulsivo, impropio del orden que se debe observar, en la vida social. Que el tema de los intérpretes producía roces, se echa de ver en el hecho de que tuviera que recurrir al General. Consta que, una vez, el superior, por diferencias que habran tenido en la casa con sus intérpretes, lo mandó que fuera al comedor y permaneciera de rodillas hasta que él le avisara. Tuvieron que interceder otros de la comunidad para que le mandara recado más de media hora después de que se podía levantar.

El que acostumbrara comer en segunda mesa, sobre todo los domingos, cuando decía la misa de once; el que no asistiera a quietes y recreaciones, les hacia llegar a la conclusión de que no era para una vida de comunidad. Es cierto que habra comunicación, tanto en el apostolado como en lo espiritual, pero eso

74. Ibid., pp. 107, 222, 258-259.

75. lbrd., pp. 209, 319, 322, 325, 326, 330.

76. $l b i d .$, pp. $209,315,319,322,325,326,330$.

77. lbid., pp. 543-544.

78. lbid., pp. 115, 219-220, 323.

79. Ibrd., pp. 159-160, 162. 
les debía parecer insuficiente. Es cierto que pedía permiso, en cada caso, al rector y obedecía sus órdenes, pero eso no bastaba. Sin embargo, al ver la devoción desbordante de la gente y la petición, que fue, en realidad exigencia, de las autoridades de que no se celebrara un funeral apresurado y simple, sino solemne ${ }^{80} ; y$, después de haberlo velado, al ver que la devoción no era pasajera, al escuchar el desconsuelo de los negros y los testimonios de la gente, ¿cómo no volvieron sobre si, tratando de descubrir la fuerza de lo que también ellos habian visto, pero que había quedado neutralizado por lo que les parecía negativo? ¿No indica falta de espíritu no llegar a discemir esas virtudes heroicas y comprender que lo que vefan como defectos o no lo eran o tenf́a explicación o no opacaba de ningún modo lo extraordinariamente bueno que relucía en su persona?

Por lo menos, habría que decir que el hermano Nicolás recuerda que, después de morir, no se acordaron de aplicarle, como es regla, indulgencias y otros sufragios, y que el olvido se debió al concepto que tenían de él, que las parecía evidente que no los necesitaba". También declara que el superior le ordenó ocho o diez d́́as después de su muerte, "que anotara todo cuanto supiera sobre sus virtudes y ministerios apostólicos"ß2.

Pedro Claver no fue un ideólogo. No se dedicó a elaborar teorías, ni predicaba máximas generales. No predicó nunca contra la esclavitud de los negros. Trató de mediar entre ellos y sus amos, insistiendo con éstos en que los trataran bien y no los castigaran y procurando que cesaran el castigo, si los esclavos habían incurrido en una falta grave, y ayudando a los negros a que se respetaran a sf mismos y, por tanto, que cumplieran con sus obligaciones ${ }^{83}$. Pero más allá de esos oficios, lo más característico suyo fue el modo como se relacionó con ellos. El les decia, desde que los recibía en los barcos, que los habían traido para servirse de ellos. Pues bien, Claver estaba a su servicio. Y de tal modo que las relaciones que entabló con ellos fueron absolutamente trascendentes. No expresaban las posibilidades de la situación. Expresaban, de modo concretísimo, el seguimiento de Jesús, en su circunstancia. Una persona normal no hubiera podido hacer lo que él hizo. La hipótesis sería que ése era el nivel dominante entre los padres de la Compañía, y por eso, la incomprensión, ya que su proceder evidenciaba, de forma involuntaria, la falta de radicalidad evangélica, en que se movian. Al no reconocerla, ya que aceptaban la estima que se tenía de ellos como expresión de lo mejor del establecimiento, que no podemos olvidar que era un establecimiento cristiano, la reacción fue el resentimiento inconsciente.

80. Ibid., pp. $439-444$.

81. Ibíd., p. 448.

B2. Ibid., pp. 247, 334.

83. Ibid., pp. 194, 300, 320, 328. 
La gente captó que Claver hizo lo que hizo, porque era la presencia de la trascendencia humanizadora del Espíritu de Jesús. Sólo por eso lo soportó y hasta le pareció bien. No lo interpretó como subversivo, sino como trascendente. Por eso, tantas personas colaboraron con él; por eso, tantos discriminados por él testificaron a su favor. No pudieron dejar de reconocer en su actuación la misma misericordia de Jesús, la del propio Dios. Esa fue también la apreciación del abogado de la causa, en respuesta a las objeciones del defensor de la $\mathrm{fe}^{\text {b4 }}$.

84. Ibid., pp. 561-565. 